\title{
OPHTHALMOSCOPIC EXAMINATION* \\ INCLUDING MEASUREMENT OF SELECTED RETINAL ARTERIOLES IN 15 CASES OF PRE-ECLAMPTIC TOXAEMIA
}

BY

\author{
MARJORY B. SNODGRASS
}

The Eye Infirmary, Glasgow

OPHTHALMOSCOPIC examination of patients with suspected pre-eclamptic toxaemia may be of help in differentiating between this condition and a preexisting hypertension of "essential" or other origin; and repeated observations may show changes reflecting the general trend of the patient towards eclampsia or recovery. Descriptions of alterations in the retinal arterioles in pre-eclamptic toxaemia are numerous; these include toxic dilatation in the early stages (Bardsley, 1917), transient spasm of an arteriole (Mylius, 1928), and uniform or irregular spasticity in smaller branches (Selinger, 1937). It was therefore decided to examine the ocular fundi of patients suffering from pre-eclamptic toxaemia during and after the termination of pregnancy, taking particular note of the calibre of retinal arterioles.

Over a period of 7 months all suitable patients who were admitted to the wards of Dr. John Hewitt, Royal Maternity and Women's Hospital, Glasgow, with pre-eclamptic toxaemia were examined; the diagnosis was made on the clinical picture with particular regard to the presence of hypertension, oedema, and albuminuria. Severe cases of pre-eclamptic toxaemia had to be excluded because the proposed examination involved considerable co-operation and concentration from the patient, and the dazzle from the beam of the ophthalmoscope for a period of half to one hour could be sufficient to precipitate an eclamptic convulsion. A total of twenty patients was examined, but in only fifteen of these was it possible to make a complete post-natal examination.

At the first examination the clinical features with particular reference to ocular symptoms were noted and, after an estimation of the refraction, the ocular fundi were examined in detail and the calibre of portions of selected arterioles was measured with a measuring ophthalmoscope according to the method previously described (Snodgrass, 1958). The vessels chosen for measurement were branches of the nasal and temporal arterioles about three or four disc diameters from the optic disc. (Vessels near the periphery were difficult to measure accurately as the image of the measuring grid was distorted in this area.) Where possible a section of an arteriole in each quadrant of both eyes was measured. The same sections were again measured 
after the termination of the pregnancy and any change in the fundus picture was noted. If ganglionic blocking agents were used diagnostically, direct observation and measurement of a selected arteriole was carried out during and after completion of the test.

Brief case notes and more detailed ophthalmoscopic descriptions of the fifteen patients are given below. The fundi are described as "healthy" when they fulfil the following criteria:

The media are clear;

The optic discs are clearly defined and pink;

The retinal arterioles are neither too straight nor unduly tortuous, not appearing unduly bright nor pale, and their branches form the expected angle with the parent trunk; at arterio-venous crossings the vein is just visible through the artery and there is no nipping of the vein;

No retinal oedema, haemorrhage, pigmentary upset, or exudate is noted.

The measurements of the retinal arterioles are relative, but in patients with a refractive error of 5 dioptres or less they are almost absolute when the ophthalmoscope is near the anterior focal point as in the method used here. Only Cases 1 and 8 had a refractive error of more than five dioptres. The results are shown in the Table (overleaf).

\section{Case Reports}

Case 1, aged 29 years, had previously had six normal pregnancies. During the present pregnancy, occasional mild frontal headaches were complained of and during the 34th week hypertension was noted. The highest blood pressure recorded was $180 / 110 \mathrm{~mm}$. $\mathrm{Hg}$. There was slight oedema at this time, but no albuminuria. The blood pressure fell slowly with medical treatment and after surgical induction there was spontaneous delivery of a full-term healthy child. The puerperium was uneventful. When the patient was examined 7 months after delivery, there were no ocular symptoms. The blood pressure was $180 / 85 \mathrm{~mm}$. $\mathrm{Hg}$, and there was no oedema or albuminuria.

Ophthalmoscopic examination at the 36th week of pregnancy showed moderately myopic fundi with healed, diffuse choroidal degeneration. The retinal arterioles appeared healthy apart from sectoral narrowing in the right inferior temporal artery near the disc. On examination 7 months after delivery the sectoral narrowing had disappeared and a significant increase in the measured calibre of the selected portions of arterioles was noted in two out of the seven arterioles measured.

Case 2, aged 27 years, was a primigravida. Oedema and hypertension were noted in the 32nd week of pregnancy. The highest blood pressure recorded was $170 / 115 \mathrm{~mm}$. $\mathrm{Hg}$. At this time, oedema was marked and there was four parts Esbach of albumen in the urine. A severe throbbing headache, without visual upset, was present. T.E.A.B. and "Vegolysen" tests produced neither a hypotensive response, nor measurable variation in retinal vessel calibre. There was much improvement on medical treatment. Surgical induction at term was followed by forceps delivery of a healthy child. There was post-partum haemorrhage. The blood pressure, oedema, and albuminuria rapidly subsided after delivery and when she was seen 6 months later there were no ocular symptoms, and the blood pressure was $130 / 85 \mathrm{~mm}$. Hg: there was a trace of albuminuria but no oedema.

Ophthalmoscopic examination at the 34th week of pregnancy showed emmetropic fundi. The retinal arterioles were unduly pale and showed generalized pathological 
TABLE

RESULTS IN FIFTEEN CASES

\begin{tabular}{|c|c|c|c|c|c|c|c|c|c|c|c|c|c|}
\hline \multirow{3}{*}{$\begin{array}{c}\text { Case } \\
\frac{1}{1}\end{array}$} & \multirow{3}{*}{$\begin{array}{l}\begin{array}{c}\text { Blood } \\
\text { Pressure } \\
\text { (mm. Hg) }\end{array} \\
\text { (a) } 180 / 110 \\
\text { (b) } 130 / 85\end{array}$} & \multirow{3}{*}{$\frac{\text { Oedema }}{\frac{\text { TR }}{-}}$} & \multirow{3}{*}{$\begin{array}{c}\begin{array}{c}\text { Album- } \\
\text { inuria }\end{array} \\
- \\
-\end{array}$} & \multicolumn{10}{|c|}{$\begin{array}{c}\text { Measurement in Gauge Widths of Calibre } \\
\text { of Arterioles }\end{array}$} \\
\hline & & & & \multicolumn{5}{|c|}{ Nasal } & \multicolumn{5}{|c|}{ Temporal } \\
\hline & & & & $\begin{array}{l}3 \cdot 5 \\
5 \cdot 0\end{array}$ & \begin{tabular}{|l|}
$5 \cdot 0$ \\
$5 \cdot 5$
\end{tabular} & \begin{tabular}{|l|}
$3 \cdot 5$ \\
$4 \cdot 5$
\end{tabular} \mid & $\left|\begin{array}{l}5 \cdot 5 \\
6 \cdot 0\end{array}\right|$ & & $\begin{array}{l}5 \cdot 0 \\
5 \cdot 0\end{array}$ & $\begin{array}{l}6 \cdot 5 \\
6 \cdot 5\end{array}$ & $\mid \begin{array}{r}7 \cdot 5 \\
7 \cdot 5\end{array}$ & & \\
\hline 2 & $\begin{array}{l}\text { (a) } 170 / 115 \\
\text { (b) } 130 / 85\end{array}$ & ++ & $\stackrel{++}{\text { TR }}$ & $\begin{array}{l}3 \cdot 0 \\
3 \cdot 5\end{array}$ & $\begin{array}{l}3 \cdot 5 \\
4 \cdot 0\end{array}$ & \begin{tabular}{|l|}
$3 \cdot 5$ \\
$4 \cdot 0$
\end{tabular} & \begin{tabular}{|l|}
$3 \cdot 0$ \\
$4 \cdot 0$
\end{tabular} & & $\begin{array}{l}4 \cdot 0 \\
4 \cdot 5\end{array}$ & $\begin{array}{l}4 \cdot 0 \\
4 \cdot 0\end{array}$ & \begin{tabular}{|}
$4 \cdot 0$ \\
$4 \cdot 0$
\end{tabular} & $\begin{array}{l}4 \cdot 0 \\
5 \cdot 0\end{array}$ & $\begin{array}{l}4 \cdot 0 \\
5 \cdot 0\end{array}$ \\
\hline 3 & $\begin{array}{l}\text { (a) } 200 / 120 \\
\text { (b) } 210 / 110\end{array}$ & $\underset{-}{\mathrm{TR}}$ & - & $\begin{array}{l}4 \cdot 5 \\
5 \cdot 0\end{array}$ & $\left|\begin{array}{|l|}4 \cdot 0 \\
4 \cdot 0\end{array}\right|$ & \begin{tabular}{|l|}
$4 \cdot 0$ \\
$4 \cdot 0$
\end{tabular} & \begin{tabular}{|l|}
$5 \cdot 0$ \\
$4 \cdot 5$
\end{tabular} & & $\begin{array}{l}3 \cdot 0 \\
3 \cdot 5\end{array}$ & $\begin{array}{l}4 \cdot 5 \\
4 \cdot 5\end{array}$ & \begin{tabular}{|l|}
$5 \cdot 5$ \\
$5 \cdot 0$
\end{tabular} & \begin{tabular}{|l|}
$3 \cdot 0$ \\
$3 \cdot 0$
\end{tabular} & \\
\hline 4 & $\begin{array}{l}\text { (a) } 190 / 120 \\
\text { (b) } 135 / 75\end{array}$ & + & + & $\begin{array}{l}4 \cdot 0 \\
4 \cdot 0\end{array}$ & $\begin{array}{l}3 \cdot 0 \\
3 \cdot 0\end{array}$ & $\begin{array}{l}4 \cdot 0 \\
4 \cdot 5\end{array} \mid$ & $\begin{array}{l}3 \cdot 5 \\
5 \cdot 5\end{array}$ & $\begin{array}{l}3 \cdot 5 \\
4 \cdot 5\end{array}$ & $\begin{array}{l}5 \cdot 5 \\
7 \cdot 0\end{array}$ & $\begin{array}{l}5 \cdot 5 \\
7.0\end{array}$ & $\begin{array}{l}5.0 \\
5.0\end{array}$ & \begin{tabular}{|l|}
$4 \cdot 0$ \\
$5 \cdot 0$
\end{tabular} & \\
\hline 5 & $\begin{array}{l}\text { (a) } 180 / 115 \\
\text { (b) } 135 / 78\end{array}$ & ++ & $\begin{array}{l}++ \\
\text { TR }\end{array}$ & $\begin{array}{l}5 \cdot 0 \\
5 \cdot 0\end{array}$ & $\begin{array}{l}3 \cdot 5 \\
3 \cdot 5\end{array}$ & & & & $\begin{array}{l}4 \cdot 0 \\
4 \cdot 0\end{array}$ & $\begin{array}{l}6 \cdot 0 \\
6 \cdot 0\end{array}$ & & & \\
\hline 6 & $\begin{array}{l}\text { (a) } 175 / 110 \\
\text { (b) } 135 / 88\end{array}$ & $\stackrel{\mathrm{TR}}{-}$ & + & $\begin{array}{l}5 \cdot 0 \\
6 \cdot 0\end{array}$ & $\begin{array}{l}4 \cdot 5 \\
5 \cdot 0\end{array}$ & \begin{tabular}{|l|}
$3 \cdot 5$ \\
$5 \cdot 0$
\end{tabular} & \begin{tabular}{|l|}
$5 \cdot 0$ \\
$4 \cdot 5$
\end{tabular} & & $\begin{array}{l}2 \cdot 0 \\
2 \cdot 0\end{array}$ & \begin{tabular}{|l|}
$3 \cdot 5$ \\
$5 \cdot 0$
\end{tabular} & \begin{tabular}{|l|}
$3 \cdot 5$ \\
$4 \cdot 0$
\end{tabular} & \begin{tabular}{|l|}
$3 \cdot 5$ \\
$4 \cdot 0$
\end{tabular} & $\begin{array}{l}3 \cdot 5 \\
4 \cdot 5\end{array}$ \\
\hline 7 & $\begin{array}{l}\text { (a) } 160 / 115 \\
\text { (b) } 150 / 100\end{array}$ & \pm & $\begin{array}{c}++ \\
-\end{array}$ & $\begin{array}{l}3 \cdot 0 \\
4 \cdot 0\end{array}$ & $\begin{array}{l}3 \cdot 5 \\
4 \cdot 0\end{array}$ & \begin{tabular}{|l|}
$4 \cdot 0$ \\
$4 \cdot 5$
\end{tabular} & \begin{tabular}{|l|}
$3 \cdot 5$ \\
$4 \cdot 5$
\end{tabular} & & $\begin{array}{l}6 \cdot 0 \\
5 \cdot 5\end{array}$ & \begin{tabular}{|l|}
$5 \cdot 5$ \\
$5 \cdot 0$
\end{tabular} & $\begin{array}{l}6 \cdot 0 \\
5 \cdot 5\end{array}$ & $\begin{array}{l}4 \cdot 0 \\
5 \cdot 5\end{array}$ & \\
\hline 8 & $\begin{array}{l}\text { (a) } 150 / 100 \\
\text { (b) } 156 / 55\end{array}$ & $\stackrel{\text { TR }}{-}$ & - & $\begin{array}{l}4 \cdot 0 \\
4 \cdot 0\end{array}$ & $\begin{array}{l}4 \cdot 0 \\
4 \cdot 0\end{array}$ & & & & $\begin{array}{l}3 \cdot 0 \\
4 \cdot 5\end{array}$ & & & & \\
\hline 9 & $\begin{array}{l}\text { (a) } 175 / 120 \\
\text { (b) } 145 / 95\end{array}$ & $\stackrel{+}{-}$ & $\overline{-}$ & $\begin{array}{l}4 \cdot 0 \\
4 \cdot 0\end{array}$ & \begin{tabular}{|}
3.0 \\
3.0
\end{tabular} & \begin{tabular}{|l|}
$2 \cdot 0$ \\
$\mathbf{3} \cdot \mathbf{0}$
\end{tabular} & $\begin{array}{l}4 \cdot 0 \\
4 \cdot 0\end{array}$ & & $\begin{array}{l}4 \cdot 0 \\
4 \cdot 0\end{array}$ & $\begin{array}{l}2 \cdot 0 \\
2 \cdot 0\end{array}$ & \begin{tabular}{|l|}
4.0 \\
4.0
\end{tabular} & $\begin{array}{l}5 \cdot 0 \\
5 \cdot 0\end{array}$ & \\
\hline 10 & $\begin{array}{l}\text { (a) } 180 / 110 \\
\text { (b) } 160 / 90\end{array}$ & $\stackrel{\text { TR }}{-}$ & $\begin{array}{l}\text { TR } \\
-\end{array}$ & $\begin{array}{l}3 \cdot 0 \\
4.0\end{array}$ & \begin{tabular}{|l|}
$3 \cdot 0$ \\
$4 \cdot 0$
\end{tabular} & & & & $\begin{array}{l}4 \cdot 0 \\
5 \cdot 0\end{array}$ & $\begin{array}{l}5 \cdot 0 \\
5 \cdot 5\end{array}$ & & & \\
\hline 11 & $\begin{array}{l}\text { (a) } 170 / 110 \\
\text { (b) } 120 / 80\end{array}$ & $\begin{array}{c}\text { TR } \\
-\end{array}$ & $\begin{array}{l}++ \\
\text { TR }\end{array}$ & $\begin{array}{l}4 \cdot 5 \\
5 \cdot 0\end{array}$ & \begin{tabular}{|l|}
3.0 \\
3.5
\end{tabular} & \begin{tabular}{|l|}
$2 \cdot 5$ \\
$3 \cdot 5$ \\
\end{tabular} & \begin{tabular}{|l|}
$3 \cdot 0$ \\
$3 \cdot 0$
\end{tabular} & & $\begin{array}{l}4 \cdot 0 \\
4 \cdot 0\end{array}$ & $\begin{array}{l}4 \cdot 0 \\
4 \cdot 0\end{array}$ & \begin{tabular}{|l|}
$4 \cdot 0$ \\
4.0
\end{tabular} & \begin{tabular}{|l|}
$3 \cdot 0$ \\
$3 \cdot 0$
\end{tabular} & \\
\hline 12 & $\begin{array}{l}\text { (a) } 130 / 85 \\
\text { (b) } 120 / 75\end{array}$ & + & - & $\begin{array}{l}4 \cdot 5 \\
4 \cdot 5\end{array}$ & $\begin{array}{l}2.5 \\
3.5\end{array}$ & $\begin{array}{l}4 \cdot 0 \\
4 \cdot 0 \\
\end{array}$ & \begin{tabular}{|l|}
$4 \cdot 0$ \\
$4 \cdot 5$
\end{tabular} & & $\begin{array}{l}4 \cdot 0 \\
5 \cdot 0\end{array}$ & \begin{tabular}{|l|}
$4 \cdot 0$ \\
$4 \cdot 0$
\end{tabular} & $\begin{array}{l}5 \cdot 0 \\
5 \cdot 0\end{array}$ & \begin{tabular}{|l|}
$4 \cdot 0$ \\
$4 \cdot 0$
\end{tabular} & \\
\hline 13 & $\begin{array}{l}\text { (a) } 180 / 120 \\
\text { (b) } 140 / 90\end{array}$ & + & + & $\begin{array}{l}4 \cdot 0 \\
4 \cdot 0 \\
\end{array}$ & $\begin{array}{l}4 \cdot 0 \\
4 \cdot 0 \\
\end{array}$ & \begin{tabular}{|l|}
$4 \cdot 0$ \\
$5 \cdot 0$ \\
\end{tabular} & \begin{tabular}{|l|}
$4 \cdot 0$ \\
$5 \cdot 5$ \\
\end{tabular} & & \begin{tabular}{|l|}
$3 \cdot 0$ \\
$4 \cdot 0$ \\
\end{tabular} & \begin{tabular}{|l|}
$3 \cdot 0$ \\
$4 \cdot 0$ \\
\end{tabular} & \begin{tabular}{|l|}
$4 \cdot 0$ \\
$5 \cdot 0$
\end{tabular} & \begin{tabular}{|l|}
$2 \cdot 5$ \\
$3 \cdot 0$ \\
\end{tabular} & \\
\hline 14 & $\begin{array}{l}\text { (a) } 168 / 100 \\
\text { (b) } 150 / 95\end{array}$ & $\stackrel{\text { TR }}{-}$ & - & $\begin{array}{l}5 \cdot 0 \\
4 \cdot 5\end{array}$ & \begin{tabular}{|}
$5 \cdot 0$ \\
$3 \cdot 5$
\end{tabular} & $\begin{array}{l}4 \cdot 0 \\
4 \cdot 0\end{array}$ & $\begin{array}{l}5 \cdot 0 \\
3 \cdot 5\end{array}$ & & $\begin{array}{l}4 \cdot 0 \\
3.0\end{array}$ & \begin{tabular}{|l|}
$4 \cdot 5$ \\
$4 \cdot 5$
\end{tabular} & \begin{tabular}{|l|}
2.5 \\
4.0
\end{tabular} & \begin{tabular}{|l|}
$3 \cdot 5$ \\
$3 \cdot 0$
\end{tabular} & \\
\hline 15 & $\begin{array}{l}\text { (a) } 180 / 115 \\
\text { (b) } 130 / 80\end{array}$ & + & $\begin{array}{l}++ \\
\text { TR }\end{array}$ & $\begin{array}{l}4.0 \\
4.0\end{array}$ & $\mid \begin{array}{l}3 \cdot 0 \\
3 \cdot 0\end{array}$ & $\begin{array}{l}2 \cdot 5 \\
2 \cdot 5\end{array}$ & \begin{tabular}{|r|}
$3 \cdot 0$ \\
$4 \cdot 0$
\end{tabular} & $\begin{array}{l}4 \cdot 0 \\
4 \cdot 5\end{array}$ & \begin{tabular}{|l|}
$4 \cdot 0$ \\
$4 \cdot 0$
\end{tabular} & \begin{tabular}{|l|}
$3 \cdot 0$ \\
$5 \cdot 0$
\end{tabular} & \begin{tabular}{|l|}
$3 \cdot 5$ \\
$4 \cdot 0$
\end{tabular} & \begin{tabular}{|l|}
$4 \cdot 0$ \\
$5 \cdot 0$
\end{tabular} & \\
\hline
\end{tabular}

(a) Highest blood pressure during pregnancy $(\mathrm{mm} . \mathrm{Hg}$ ).

(b) Blood pressure after puerperium $(\mathrm{mm} . \mathrm{Hg})$.

narrowing. Patches of retinal oedema were present near the right inferior nasal artery. On examination 6 months after delivery, the fundi appeared healthy. A significant increase in the measured calibre of the selected portions of arterioles was noted in three out of the nine arterioles measured. 
Case 3, aged 36 years, had previously had one pregnancy which was terminated by Caesarian section because of the presence of hypertension and placenta praevia. In the present pregnancy, the patient had twice been admitted to hospital because of hypertension, and was admitted again in the 36th week. There was an occasional dull frontal headache, but no visual upset. The highest blood pressure recorded was $200 / 120 \mathrm{~mm}$. Hg. There was a trace of oedema at this time, but no albuminuria. The T.E.A.B. diagnostic test showed a hypotensive response from $182 / 105$ to $148 / 88 \mathrm{~mm}$. Hg. Coinciding with the maximum fall in blood pressure, a branch of the left upper nasal artery was observed to dilate from gauge width " 4 " to " 5 " for three seconds. The blood pressure settled a little on routine treatment. Forceps delivery at term resulted in the birth of a healthy child. Shortly after this, the blood pressure fell to $170 / 95 \mathrm{~mm} . \mathrm{Hg}$ and the oedema and albuminuria disappeared. At a subsequent examination 4 months after delivery, the blood pressure had risen again to $210 / 110 \mathrm{~mm}$. $\mathrm{Hg}$.

Ophthalmoscopic examination in the 36th week of pregnancy revealed low myopia. The arterioles showed marked calibre variations and slight pallor of the blood columns in the narrower portions. At arterio-venous crossings there was faint obscuration, but no nipping of the veins. Examination 4 months after delivery showed no change in the general fundus picture and no significant change in the calibre measurements.

Case 4, aged 28 years, was a primigravida. Oedema was noted in the 31 st week of pregnancy and the following week she was admitted to hospital. There was no history of headache or visual upset. The highest blood pressure recorded was 190/120 mm. Hg. At this time oedema was marked and there was ten parts Esbach of albumen in the urine. Intra-uterine death followed, and mixed accidental haemorrhage and still-birth occurred in the 37th week. The blood pressure returned to normal and the oedema and albuminuria disappeared in the puerperium. The patient was seen post-natally one week, and again 6 months after delivery when there was no oedema or albuminuria and blood pressures of $130 / 80$ and $130 / 70 \mathrm{~mm}$. $\mathrm{Hg}$ were recorded.

Ophthalmoscopic examination at the 35th week of pregnancy showed low hypermetropic astigmatism. The larger arterioles had a broader reflex than usual, but showed no calibre change. There was marked straightening and narrowing of the smaller arterioles and some pallor. The arterio-venous crossings showed slight obscuration with, in one crossing, nipping of the vein. There were three small striate haemorrhages in the right fundus. During a T.E.A.B. diagnostic test the blood pressure fell from 180/105 to 160/95 $\mathrm{mm}$. Hg. Coinciding with the maximum fall in blood pressure, an evanescent, measured, irregular dilatation was observed in a small branch of the right inferior nasal artery from gauge width " 1 " to " 2 ".

On the first post-natal examination one week after delivery, a soft exudate and a small striate haemorrhage were noted near the left disc and one of the nine arterioles previously measured showed appreciable dilatation. On the second examination 5 months after delivery, spasticity of the small branches of the arterioles had disappeared as also had the haemorrhages. The appearances of the arterio-venous crossings were unchanged. Five of the nine arterioles previously measured showed appreciable dilatation.

Case 5, aged 23 years, was a primigravida. She was admitted in the early months of pregnancy on account of hypertension. She was re-admitted in the 34th week when she suffered from severe frontal headaches. On four occasions she saw flashes of light "like forked lightning" preceding frontal headaches. There were also momentary spots before the eyes "like black dots with haloes round them" which were unrelated to the headaches. The highest blood pressure recorded was $180 / 115 \mathrm{~mm}$. Hg. Oedema was then marked and there was twenty parts Esbach of albumen in the urine. As there was no improvement in the general condition on medical treatment, Caesarian section was performed in the 37 th week of pregnancy. In the puerperium, the blood pressure was 135/80 
$\mathrm{mm}$. $\mathrm{Hg}$, oedema had disappeared, and the albuminuria became less than one part Esbach. When she was seen 4 months after delivery, the blood pressure was $135 / 78 \mathrm{~mm}$. $\mathrm{Hg}$; there was a very faint trace of albuminuria and no visual upset. Headaches were less severe.

Owing to the gravity of the patient's condition in the 36th week of pregnancy, only one eye was examined. It was emmetropic, and pallor and narrowness of some of the very small arterioles were noted, but otherwise the fundus was healthy. Examination 4 months after delivery showed a healthy fundus. Measurement of four arterioles showed no significant alteration in calibre post-natally.

Case 6, aged 37 years, had previously had one normal pregnancy and one miscarriage. In the present pregnancy, the antenatal health was good until the 37 th week when she was admitted on account of hypertension. There were no ocular symptoms. The highest recorded blood pressure was $175 / 110 \mathrm{~mm}$. $\mathrm{Hg}$. Albuminuria then recorded was two parts Esbach and there was a faint trace of oedema. Spontaneous delivery of a healthy premature child followed surgical induction in the 38th week. The puerperium was normal. On examination 2 months after delivery the blood pressure was $135 / 88 \mathrm{~mm}$. $\mathrm{Hg}$, with no oedema or albuminuria.

Ophthalmoscopic examination in the 37th week of pregnancy showed emmetropic fundi. Narrowing of the right upper temporal artery and definite irregularity of calibre in many small branches of the retinal arterioles were noted. Examination 2 months after delivery showed that the calibre variation had disappeared although the narrow appearance of the right upper temporal artery was still present. Calibre measurement showed a significant dilatation in four of eight arterioles measured post-natally.

Case 7, aged 34 years, had previously had two pregnancies accompanied by pre-eclamptic toxaemia and post-partum eclampsia. During the present pregnancy, the patient had twice been in hospital because of hypertension before being again admitted in the 32nd week of pregnancy when she gave a history of intermittent vomiting and of transient floating black spots in front of her eyes. She had no headache. The highest blood pressure recorded was $160 / 115 \mathrm{~mm}$. Hg. There was moderate oedema and sixteen parts Esbach of albumen at this time. At the 36th week of pregnancy, labour was surgically induced as there was little response to medical treatment. In the puerperium, the appearance of spots in front of the eyes continued, vomiting ceased, oedema disappeared, the blood pressure was $160 / 105 \mathrm{~mm}$. $\mathrm{Hg}$, and there was two parts Esbach of albumen. In two examinations, 2 months and 6 months after delivery, there were no symptoms and the blood pressure was $155 / 105$ and $150 / 100 \mathrm{~mm}$. Hg. Albumen was present in urine in the first examination but absent in the second.

In the 34th week of pregnancy, ophthalmoscopic examination of hypermetropic fundi. showed, in the right eye, a choroidal rupture (from a childhood contusion injury). In both eyes, the arterioles were slightly paler in colour than usual, but only in a few small branches was any definite narrowing noted. Marked calibre variation was present in the left nasal artery. There was very slight obscuration of the veins at most of the large arterio-venous crossings. One small striate haemorrhage was seen in the midperiphery of the left fundus. 2 and 6 months after delivery the calibre variation in the arterioles and the haemorrhage had disappeared. The obscuration of the veins at the arterio-venous crossings was unchanged.

Measurement of nine arterioles showed appreciable dilatation in three of them postnatally.

Case 8, aged 36 years, had a history of one miscarriage and two pregnancies complicated by raised blood pressure. She was always subject to migrainous headaches, which were much less frequent during her pregnancies. In the present pregnancy, the patient was 
admitted in the seventeenth week on account of a blood pressure of $150 / 100 \mathrm{~mm}$. $\mathrm{Hg}$. A trace of oedema but no albuminuria was found. She was symptom-free. Her blood pressure settled on rest and she was re-admitted in the 31st week when the blood pressure was $140 / 90 \mathrm{~mm} . \mathrm{Hg}$, and there was slight oedema and a trace of albumen in the urine. A T.E.A.B. diagnostic test carried out in her first admission showed no fall in blood pressure and no change in ophthalmoscopic appearance or measurement of the retinal blood vessels. In the 39th week of pregnancy, she had a spontaneous delivery. In the puerperium the blood pressure was $160 / 100 \mathrm{~mm}$. $\mathrm{Hg}$ and there was no oedema or albumen in the urine. When examined 6 months after delivery, she had frontal headaches, worse on stooping, and occasional dizzy turns. The blood pressure was $165 / 55 \mathrm{~mm}$. $\mathrm{Hg}$ and there was no oedema or albuminuria.

Ophthalmoscopic examination in the 32nd week of pregnancy, showed highly myopic fundi in which fine detail was obscured by cortical lens opacities in the left eye. The blood vessels appeared healthy except for a slight calibre variation in the main arterioles of the left eye. On examination 6 months after delivery, the calibre variation previously noted had disappeared. Measurement, which was difficult on account of the lens opacities in the left eye and the patient's inability to maintain accurate fixation, was carried out in only three vessels, one of which showed appreciable dilatation post-natally.

Case 9, aged 38 years, had previously had seven normal pregnancies. She was admitted in the 35th week of pregnancy on account of raised blood pressure. She complained of occasional mild frontal headaches, but had no visual upset. The highest recorded blood pressure was $175 / 120 \mathrm{~mm}$. $\mathrm{Hg}$. Oedema was present but there was no albuminuria. The hypertension gradually subsided and in the 39 th week, the pregnancy terminated spontaneously. In the puerperium, the blood pressure was $100 / 70 \mathrm{~mm}$. $\mathrm{Hg}$. There was no oedema or albuminuria. When examined post-natally the blood pressure was $145 / 95$ $\mathrm{mm}$. Hg. There was no oedema or albuminuria.

Ophthalmoscopic examination, in the 36th week of pregnancy, of hypermetropic fundi showed a broadened reflex on the larger retinal arterioles and a few small branches which were pale and very narrow. Light sheathing and irregularity of calibre of the inferior nasal artery of the left eye were present. In the large arterio-venous crossings, there was obscuration of the veins by the arterioles.

Examination 6 weeks after delivery showed no appreciable change in the fundus picture. Measurement of eight arterioles showed dilatation in one of them post-natally.

Case 10, aged 26 years, was a primigravida. She was admitted in the 36 th week of pregnancy because of hypertension. She had occasional spots "like midges" in front of the eyes and mild frontal headaches. There was no other visual upset. The highest recorded blood pressure was $180 / 110 \mathrm{~mm}$. $\mathrm{Hg}$, at which time there was a trace of oedema and half part Esbach of albumen in the urine. A T.E.A.B. test produced no hypotensive response and no ophthalmoscopic change in the calibre of the observed retinal blood vessels. There was little improvement on medical treatment. Surgical induction in the 38th week of pregnancy was followed by forceps delivery of a healthy child. The blood pressure fell to $160 / 90 \mathrm{~mm}$. $\mathrm{Hg}$, and there was no oedema or albuminuria in the puerperium. When she was examined post-natally there were no symptoms. Blood pressure was 140/80 $\mathrm{mm} . \mathrm{Hg}$ and there was no oedema or albuminuria.

Ophthalmoscopic examination in the 36th week of pregnancy was carried out in the right eye only owing to the patient's nervousness. There was low myopia. The arterioles were slightly pale and appeared slightly narrow although no variation in calibre was seen. One small area of retinal oedema was noted near the upper temporal artery; 5 months after delivery there was no pallor in the retinal arterioles although the blood vessels still appeared slightly narrow. There was no retinal oedema. Measurement of four arterioles showed dilatation in three of them. 
Case 11, aged 19 years, was a primigravida who was admitted in the 37th week of pregnancy on account of the development of hypertension and albuminuria in the previous 2 weeks. On two occasions she saw black spots with haloes round them "like eyes" floating across her field of vision, upwards and to the right. She had no headaches. The highest recorded blood pressure was $170 / 110 \mathrm{~mm}$. Hg. At this time there was a trace of oedema and twelve parts Esbach of albumen in the urine. There was much improvement in the condition on medical treatment. In the 38th week of pregnancy, a healthy baby was spontaneously delivered. The blood pressure in the puerperium was $120 / 80 \mathrm{~mm}$. Hg. When she was seen 2 months after delivery there was no oedema and less than one part Esbach of albumen in the urine.

On ophthalmoscopic examination in the 37th week of pregnancy, the eyes were almost emmetropic and the fundi appeared healthy; 2 months after delivery, the fundus appearance was unchanged. Measurement of eight arterioles showed appreciable dilatation in one of them post-natally.

Case 12, aged 40 years, had previously had one normal pregnancy. The present pregnancy was complicated by hyperemesis in the first 3 months. In the 37th week of pregnancy, she was admitted to hospital on account of frontal headaches. The highest recorded blood pressure was $130 / 85 \mathrm{~mm}$. $\mathrm{Hg}$. Oedema was present but no albuminuria. When she was seen 5 months after delivery, the blood pressure was $120 / 75 \mathrm{~mm}$. $\mathrm{Hg}$, and there was no oedema or albuminuria. Ophthalmoscopic examination of the fundi in the 37th week of pregnancy showed hypermetropic astigmatism. There was obscuration of the veins at the arterio-venous crossings. Otherwise the fundi appeared healthy. On examination 6 months after delivery, the fundus appearance was unchanged. Measurement of eight retinal arterioles showed appreciable dilatation in two of them post-natally.

Case 13, aged 29 years, had one previous pregnancy which was complicated by hypertension. In the present pregnancy, hyperemesis was present for the first 20 weeks and aching frontal headaches from the 28th week. There was no complaint of visual upset. The patient was admitted in the 32nd week of pregnancy. The highest blood pressure recorded was $180 / 120 \mathrm{~mm} . \mathrm{Hg}$ and there was marked oedema with fourteen parts Esbach of albumen in the urine. Caesarian section was performed in this week as the medical condition had not improved. In the puerperium the blood pressure fell to $110 / 70 \mathrm{~mm}$. $\mathrm{Hg}$ and there was no oedema or albuminuria. 6 months after delivery she complained of an occasional frontal headache, her blood pressure was $140 / 90 \mathrm{~mm} . \mathrm{Hg}$, and there was no oedema or albuminuria.

Ophthalmoscopic examination in the 33rd week of pregnancy showed slightly myopic fundi with narrow straight arterioles, some with a slightly pale reflex. There was no irregularity in calibre. Examination of the fundi 6 months after delivery showed disappearance of the narrow straight appearance of the arterioles and of the pale reflex. Measurement of the calibre of eight retinal arterioles showed appreciable dilatation in five of them post-natally.

Case 14, aged 41 years, had previously had eight normal pregnancies and one miscarriage. From the 27th week of the present pregnancy the patient had seen flashing lights "like sheet lightning, though sometimes coloured", which appeared almost daily. At times, when she was reading, black spots floated across the vision from the right upwards. A throbbing "band-like" headache occasionally occurred, associated with excitement and not related to the visual upset; but when the headache was severe, mistiness of vision with occasional flashes of light and buzzing of the ears also occurred. She was admitted in the 36th week of pregnancy. The highest recorded blood pressure was $180 / 100 \mathrm{~mm}$. Hg. There was a trace of oedema but no albuminuria. Spontaneous delivery of a healthy child followed surgical induction in the 39th week of pregnancy. Blood pressure in the 
puerperium was $150 / 90 \mathrm{~mm}$. Hg. There was no oedema or albuminuria. On examination 7 months after delivery the patient stated that the ocular symptoms had gradually disappeared but oedema was occasionally present. The blood pressure was $150 / 95 \mathrm{~mm}$. Hg. There was no oedema or albuminuria.

Ophthalmoscopic examination in the 36th week of pregnancy showed low hypermetropic astigmatism. The larger retinal arterioles had an unduly bright reflex and the small branches were narrow and had a pale reflex. Arterio-venous crossings showed nipping of the veins and, in two crossings, kinking of the veins. Small venules around the maculae were more tortuous than normal. Examination 7 months after delivery showed no appreciable change. Post-natal measurement of eight arterioles showed appreciable reduction in the calibre of three and an increase in calibre of one arteriole.

The above findings suggest an underlying essential hypertension complicated by a mild pre-eclamptic toxaemia.

Case 15, aged 27 years, a primigravida, had, for years, been subject to severe headaches accompanied by nausea and lasting about 12 hours. There were no visual phenomena. These headaches remained unchanged throughout the pregnancy. Once in the 25th week of pregnancy, the patient saw a shower of black spots with golden centres spreading upwards over the vision and vanishing quickly. The patient was admitted to hospital in the 30th week when there was marked oedema and ten parts Esbach of albumen in the urine. The highest recorded blood pressure was $180 / 115 \mathrm{~mm}$. Hg. The spontaneous delivery of a healthy child occurred in the 35th week of pregnancy. In the puerperium the blood pressure fell to $130 / 80 \mathrm{~mm}$. $\mathrm{Hg}$, the oedema disappeared, and only a trace of albumen was found in the urine. When she was seen 6 months after delivery, the blood pressure was $130 / 80 \mathrm{~mm} . \mathrm{Hg}$, there was no oedema, and only a faint trace of albumen was present.

A low degree of hypermetropic astigmatism was present. Ophthalmoscopic examination showed that the larger arterioles were healthy, but that nearly every small branch was markedly narrowed from its commencement, usually irregularly. These branches were too peripheral for accurate measurement of calibre, except in one case. Examination 6 months after delivery showed complete absence of sectorial narrowing in these small arterioles. Measurement of nine arterioles showed appreciable dilatation in three of them, one of which, an obviously spastic vessel, dilated from " 3 " to" 5 " gauge widths.

\section{Comment}

The ophthalmoscopic pictures described in this series of cases of preeclamptic toxaemia correspond with the findings of other workers. The actual changes in measurement of the selected retinal arterioles confirm the clinical inference that there is frequently a narrowing of arterioles in this condition. In the present series, this narrowing was occasionally revealed by measurement, although unsuspected from the ophthalmoscopic appearance of the vessels (e.g. Case 11).

The most striking result of the investigation was that 37 arterioles ( 34 per cent.) showed a change in calibre of at least one gauge width and that this change occurred in at least one vessel, in thirteen of the fifteen cases examined. A change of this order was considered significant (Snodgrass, 1958). The changes in calibre were noted with almost equal frequency in the nasal and temporal quadrants, although it has been suggested that nasal arterioles show pathological narrowing before temporal ones (Duke-Elder, 1940). 
In Cases 3 and 5, no significant narrowing of measured arterioles was found. In the former, the blood pressure was still raised 4 months after delivery and the presence of slight retinal arteriosclerosis suggested an essential hypertension complicated by toxaemia of pregnancy. In Case 5, narrowness of many arterioles too peripheral for actual measurement was observed, although calibre changes were not found in the four measured vessels. (This patient's general condition did not permit measurement of the usual number of blood vessels.) In Case 14, three arterioles were found to be significantly smaller on the post-natal examination. This may have been due either to dilatation during pre-eclampsia (Bardsley) or more probably to progressive arteriosclerosis accompanying an underlying essential hypertension. As in Case 3, there was a history suggesting this condition.

-It is interesting to note that a hypotensive response and measurable dilatation of an arteriole during the administration of a ganglionic blocking agent occurred in two out of five cases (Cases 3 and 4).

It is felt that, in addition to routine ophthalmoscopy in antenatal examinations, regular measurement of the calibre of selected retinal arterioles might be of help in the early diagnosis of pre-eclamptic toxaemia.

This work was assisted by the Spencer Research Trust.

My thanks are due to Dr. J. Hewitt for access to his patients and records and to Dr. J. Marshall for his helpful advice.

\section{REFERENCES}

BARDSLey, P. C. (1917). Brit. J. Ophthal., 1, 239.

DUKe-ElDER, S. (1940).“ Text-book of Ophthalmology”, vol. 3, p. 2724. Kimpton, London. MyLiUs, K. (1928). Ber. ophthal. Ges. Heidelberg, 47, 379.

Selinger, E. (1937). Amer. J. Ophthal., 20, 56.

SnOdgrass, M. B. (1958). Brit. J. Ophthal., 42, 535. 